\title{
Novel Disease-Modifying Drugs against Skin Fibrosis of Systemic Sclerosis
}

\author{
Mana Nishiguchi, Yuki Yamamoto, Masatoshi Jinnin* \\ Department of Dermatology, Wakayama Medical University, Wakayama, Telephone: +81-73-447-2300, Fax: \\ +81-73-448-1908, Email: mjin@wakayama-med.ac.jp
}

\section{ABSTRACT}

Systemic sclerosis (SSc) or scleroderma is an autoimmune disorder characterized by tissue fibrosis of the skin and internal organs. The etiology of the skin fibrosis is thought to be thickened dermis due to uncontrolled excessive deposition of various extracellular matrix, mainly type I collagen.Systemic treatments with anti-inflammatory and cytotoxic immunosuppressive properties, such as corticosteroids and immunosuppressants, are usually considered for skin sclerosis of patients with SSc. However, their approach must be initiated at the early stage, before the fibrosis is completed, and the effects of the corticosteroids and immunosuppressants are known to be reduced in the late stages of the sclerosis. Furthermore, various significant adverse effects of these treatments must be considered.This paper discusses the present day understanding of therapeutic options using disease-modifying drugs against skin sclerosis of SSc patients and the possible mechanisms.

Keywords: Collagen; Scleroderma; Steroid

\section{Introduction}

Systemic sclerosis (SSc) or scleroderma is an autoimmune disorder characterized by tissue fibrosis of the skin and internal organs (e.g. lung or esophagus). The etiology of the skin fibrosis is thought to be thickened dermis due to uncontrolled excessive deposition of various extracellular matrix (ECM), mainly type I collagen. However, the mechanisms responsible for the pathologic increase of ECM in SSc skin have not been fully clarified, despite recent advances in understanding of the regulation of ECM gene expression. The current hypothesis is that inflammation, autoimmunity, and vascular abnormality may lead to activation of dermal fibroblasts, which result in the overproduction of $\operatorname{ECM}(1,2)$.

SSc patients are clinically sub grouped according to the classification system proposed by LeRoy et al. (3) either diffuse cutaneous SSc (dcSSc) or limited cutaneous SSc (1SSc). The definition of dcSSc is progressive skin sclerosis involving proximal extremities and the trunk. Systemic treatments with anti-inflammatory and cytotoxic immunosuppressive properties, such as corticosteroids and immunosuppressants, are usually consid- ered for skin sclerosis of dcSSc patients. However, their approach must be initiated at the early stage of dcSSc ('early diffuse' SSc), before the fibrosis is completed, and the effects of the corticosteroids and immunosuppressants are known to be reduced in the late stages of the sclerosis. Furthermore, various significant adverse effects of these treatments must be considered.

This paper discusses the present day understanding of therapeutic options using disease-modifying drugs against skin sclerosis of SSc patients and the possible mechanisms.

\section{Review}

\subsection{Corticosteroid}

Corticosteroid treatment for skin sclerosis of patients with SSc remains controversial because a retrospective case-control study showed that high-dose corticosteroid is a risk factor of life-threating renal crisis (4, $5)$. On the other hand, corticosteroid treatment is more commonly used in Japan, especially for patients in early stages of dcSSc.

Japanese SSc patients have lower susceptibility to renal crisis than other ethnic SSc patients. However, no 
controlled clinical trials have fully proven the efficacy of corticosteroids for treatment of skin thickening. Sharada et al. reported a randomized placebo-controlled, double-blind study on 35 patients with dcSSc in India (6). Significant improvement of total skin score (28.5 to 25.8) was seen in 17 patients received monthly intravenous dexamethasone pulse therapy (100 $\mathrm{mg}$ dexamethasone in $250 \mathrm{ml} \mathrm{5 \%} \mathrm{dextrose)} \mathrm{for} \mathrm{six} \mathrm{courses,} \mathrm{but} \mathrm{not} \mathrm{in} 18$ control patients (30.6 to 34.7$)$. Contrary to concerns, adverse effects of corticosteroid therapy were limited to an increase in minor infections. On the other hand, Takehara conducted an uncontrolled prospective study of 23 Japanese patients with dcSSc, and described that low-dose oral corticosteroid (initial dose of prednisolone 20 $\mathrm{mg} /$ day $)$ significantly $(\mathrm{P}<0.001)$ reduced the mean skin score (20.3 to 12.8 ) after one year of treatment, and to 8.7 at final evaluation (7). Based on the result, the report recommended low-dose oral corticosteroid treatment for patients with two or more of following three conditions: (1) early onset; (2) edematous changes, and (3) rapid progression.

Although the mechanism of the efficacy of corticosteroid is unknown, it may involve immunosuppressive effects by inhibition of cellular activity, and by reduction of antibody production. In addition, inhibition of collagen transcription, inhibition of collagen mRNA stability, and the increase of matrix metalloproteinase (MMP) expression may also be involved in the mechanism $(8$, 9).

\subsection{Immunosuppressants}

The few controlled clinical studies of immunosuppressants to date have not always shown efficacy. Nonetheless, various immunosuppressants are widely used for the treatment for skin sclerosis of patients with dcSSc.

\section{1) Cyclophosphamide}

Cyclophosphamide is an alkylating agent that affects growth of normal and malignant cells. Cyclophosphamide is sometimes used to improve interstitial lung disease (ILD) in patients with SSc, although the mechanisms underlying the effect of cyclophosphamide on tissue fibrosis are still to be clarified. The efficacy on skin sclerosis has also been determined. In a multicenter double-blind study, Tashkin et al. reported that oral cyclophosphamide (initially $1 \mathrm{mg} / \mathrm{kg} /$ day) improved skin sclerosis as well as ILD after 12 months of treatment
(10). The skin score significantly $(\mathrm{P}<0.05)$ improved from 15.5 to 11.9 in 54 patients treated with cyclophosphamide. To note, the significant difference in improvement of the skin score in the dcSSc group disappeared after an additional year (11).

On the other hand, cyclophosphamide may cause adverse events, such as cytopenia and immunosuppression, and the risk of malignancies will be increased by the accumulating dose. Thus, to avoid side effects and to reduce the total dose, intravenous cyclophosphamide pulse therapy (IVCY) is often considered. The combination therapy of corticosteroid and IVCY for ILD of SSc has already been evaluated. One study demonstrated that prednisone $\left(10 \mathrm{mg} /\right.$ day) and IVCY $\left(750 \mathrm{mg} / \mathrm{m}^{2}\right.$ month for one year) were effective for the suppression of active alveolitis in SSc patients (12). However, other randomized control trials could not show significant effects (13), and the effect of IVCY for ILD of SSc patients remains controversial.

Previous literature has also indicated the significant efficacy of IVCY on skin sclerosis, but is made up of mainly case reports or case series $(14,15)$. Randomized control trial studies are therefore required.

\section{2) Cyclosporine $A$}

In spite of small number of patients (only 20 subjects in a single facility), a double-blind study has indicated that treatment with oral cyclosporine $(2.5$ $\mathrm{mg} / \mathrm{kg} /$ day) and monthly iloprost for one year significantly improves skin sclerosis $(\mathrm{P}=0.008)$ as well as microvascular abnormalities and esophageal involvement compared to monthly dose of iloprost alone (16). Suppression of serum IL-6 concentration was suggested to be the mechanism of the effects of cyclosporine. Further larger studies are required to confirm treatment efficacy. Furthermore, the possibility that cyclosporine induced a renal crisis in SSc patients should be considered.

\section{3) Methotrexate}

Methotrexate is a dihydrofolate reductase inhibitor, which interferes with DNA synthesis and cell production, and has been used for many human disorders. Two randomized controlled trials (29 patients with 15-25 $\mathrm{mg} /$ week in 1996 and 71 patients with 10-17.5 mg/week in 2001) showed that methotrexate improves the skin score in early dcSSc, albeit in a statistically insignificant rate at 24 weeks $(\mathrm{P}=0.06$ and $<0.17$, respectively $)(17$, 
18). Additional analyses were performed, showing significant effects of the drug on the skin score. Patients treated with methotrexate should be carefully observed for occurrence or worsening of ILD, especially Japanese SSc patients.

\section{4) Mycophenolate mofetil}

Mycophenolate mofetil inhibit inosine monophosphate dehydrogenase, and reduce proliferation of $\mathrm{T}$ and $\mathrm{B}$ cells, which resulted in immunosuppressive effects. The therapeutic values against lung, muscle, and joint involvements of SSc have been reported. Several reports have also evaluated the effect of mycophenolate mofetil for treating skin thickening in small open-label studies with small number of patients. For example, in $15 \mathrm{dcSSc}$ patients, the skin score significantly improved (22.5 to 8.4 ) in patients who tolerated the treatment (starting from $1,000 \mathrm{mg} /$ day, increased to $2-3,000 \mathrm{mg} /$ day) for $>3$ months $(\mathrm{P}<0.0001)(19)$.

However, Nihtyanova et al. retrospectively compared the effect of mycophenolate mofetil ( 2000 $\mathrm{mg} /$ day) in $109 \mathrm{SSc}$ patients and that of other immunosuppressants including azathioprine, anti-thymocyte globulin, D-penicillamine, intravenous cyclophosphamide, oral cyclophosphamide, $\alpha$-interferon and methotrexate in 63 patients, which showed no significant difference in the change of skin score between the two groups (20): 26 to 11 in mycophenolate mofetil group and 26 to 15 in control group. Accordingly, the efficacy of the drug on skin sclerosis remains controversial.

\section{5) Tacrolimus}

Morton et al. reported that oral tacrolimus (mean $0.07 \mathrm{mg} / \mathrm{kg} /$ day) improved skin sclerosis in four of eight patients in a small open-label study (21). However, the risk of renal crisis is also carefully considered in SSc patients.

\section{6) Azathioprine}

A previous randomized study showed skin score was significantly improved $(14.7$ to $5.2, \mathrm{P}<0.001)$ in 30 patients treated with cyclophosphamide $(2 \mathrm{mg} / \mathrm{kg} /$ day for 12 months, followed by $1 \mathrm{mg} / \mathrm{kg} /$ day for 6 months), but not (14.3 to 14.5) in those with azathioprine (2.5 $\mathrm{mg} / \mathrm{kg} /$ day for 12 months, followed by $2 \mathrm{mg} / \mathrm{kg} /$ day for 6 months) (22). Accordingly, this report indicated that azathioprine did not clearly affect skin sclerosis.

\subsection{Anti-thymocyte globulin}

Anti-thymocyte globulins have been used as polyclonal antibodies for the depletion of $\mathrm{T}$ lymphocytes to prevent graft-versus-host disease in organ transplantation. Several older case reports have indicated its efficacy for SSc, but in studies of 10 cases, the effect of anti-thymocyte globulins $(10 \mathrm{mg} / \mathrm{kg}$ over 4 hours, on five days) was not proven (only two patients showed improvement in the skin, whereas five patients were worse and three were stable after 12 months). Moreover, various side effects, including allergic reaction appeared (23). One recent paper described the significant $(\mathrm{P}<0.01)$ efficacy of anti-thymocyte globulin plus mycophenolate mofetil on skin score (24). Furthermore, the drug is commonly used at the time of autologous stem cell plantation in SSc patients.

\subsection{D-penicillamine}

D-penicillamine was believed to have anti-fibrotic effect, to stabilize or even to improve ILD, and to have a beneficial effect on patient survival $(25,26)$. Jayson $e t$ al. studied $22 \mathrm{SSc}$ patients and concluded that D-penicillamine $\quad(\sim 1250 \quad \mathrm{mg} /$ day $) \quad$ showed ous benefit in 15 patients, but due to either side effects or relapse, overall good results occurred in five patients (27). On the other hand, other investigators question whether D-penicillamine does indeed have a positive effect in SSc patients. For example, Clements et al. compared the effects of high-dose D-penicillamine (750 1,000 mg/day) on improvement of skin score with that of low-dose D-penicillamine $(125 \mathrm{mg} /$, every two days) in early-stage dcSSc patients, but there was no statistically significant difference $(-4.9$ vs $-6.7, \mathrm{P}=0.38)$ (28). After this double-blind study, the frequency of usage of this drug is decreased, in spite of a recent retrospective randomized cohort study showing efficacy of D-penicillamine $(750 \mathrm{mg} /$ day $)$ on skin sclerosis $(\mathrm{P}<0.01)$ (29). Side effects include cytopenia, anorexia, dysgeusia, vomiting, and diarrhea.

\subsection{Tocilizumab}

Interleukin (IL)-6 is a multifunctional proinflammatory cytokine produced by various cell types, including lymphocytes and fibroblasts. In SSc, serum levels of IL-6 is significantly elevated, and serum levels of IL-6 positively correlated with the skin score (30), suggesting the involvement of IL-6 in the pathogenesis of skin fi- 
brosis. IL-6 has already been shown to stimulate collagen production in cultured human dermal fibroblasts (31), and the possible effect of tocilizumab, a monoclonal antibody against the IL-6 receptor, on SSc skin fibrosis may be via the blockade of inflammatory response and the profibrotic effect of IL-6 on dermal fibroblasts.

The efficacy of tocilizumab on skin sclerosis has been demonstrated by case reports and case series. However, Phase 2 Safety and Efficacy of Subcutaneous Tocilizumab in Adults with Systemic Sclerosis (faSScinate) randomized controlled trial including 87 patients (43 treated with tocilizumab and 44 with placebo) showed no significant reduction in skin score by tocilizumab ( $\mathrm{P}=0.058$, subcutaneous $162 \mathrm{mg}$ weekly). The difference of skin score, however, was greater in the tocilizumab group (-6.3) than in the placebo group (-2.8) at 48 weeks (32). On the other hand, Khanna et al. described an additional report of patients with SSc who were treated for 48 weeks in an open-label extension phase of the faSScinate study with weekly $162 \mathrm{mg}$ subcutaneous tocilizumab (33). In the report, 24 out of the 44 SSc patients treated with placebo-tocilizumab, and 27 out of the $43 \mathrm{SSc}$ patients treated with continuous-tocilizumab patients completed 96-week treatments. Mean change of skin score from the baseline was -3.1 for patients with placebo and -5.6 for those with tocilizumab at week 48, and -9.4 for placebo-tocilizumab and -9.1 for continuous-tocilizumab at week 96. Accordingly, improvements to skin score were observed in placebo-treated patients who crossed over to tocilizumab and were maintained in the open-label period.

A Phase II/III, multicenter, randomized, double-blind, placebo-controlled trial is currently being performed to prove the efficacy of tocilizumab on SSc cutaneous sclerosis. In the study, patients will be randomized to receive either tocilizumab $162 \mathrm{mg}$ subcutaneously or a placebo each week for 48 weeks. Between weeks 48 and 96, all patients will receive open-label tocilizumab $162 \mathrm{mg} /$ week.

\subsection{Ritsuximab}

$\mathrm{B}$ cells are known to play various roles in the human immune system, including antibody generation to specific antigens, which are able to not only neutralize pathogens, but are also able to enhance their elimination by activating phagocytosis or complement proteins
(34). Furthermore, independent from such antibody producing function, B cells also exert important regulatory roles, including efficient antigen presentation to the $\mathrm{T}$ cells, cytokine secretion, and immune cell differentiation.

Rituximab is a chimeric monoclonal antibody for CD20 expressed on mature B cells. Since its first use in human lymphoma in the 1990s, this biologic drug has been available for various diseases. Among autoimmune diseases, ritsuximab was firstly tested in patients with rheumatoid arthritis. In non-responders to other therapies, ritsuximab was demonstrated to be effective in preventing progression of articular erosion. Since then, off-label use of ritsuximab has been reported for intractable cases of various autoimmune diseases, including systemic lupus erythematosus (SLE), autoimmune hemolytic anemia, Evans syndrome, granulomatosis with polyangiitis, pemphigus, pemphigoid, type 1 diabetes mellitus, Sjogren's syndrome and autoimmune pancreatitis.

In SLE patients, although phase II trials resulted in good tolerance and had preferable therapeutic effects, phase III double-blind placebo-controlled studies could not show significant effects in this disease. Nonetheless, many experts have regarded B cell depletion with rituximab as promising treatment for refractory lupus. Rare, but fatal side effects, such as progressive multifocal leukoencephalopathy (PML) infection, should be considered, however.

B cell abnormalities in the pathogenesis of SSc may include polyclonal B cell activation and autoantibody production. Various abnormal immune activations including the production of disease-specific autoantibodies are observed in SSc. Although such autoantibodies may not have functional roles, they are strongly correlated with unique clinical manifestations. B cell activation in SSc was also characterized by chronic hyper-reactivity of memory B cells. In addition, the percentage of IL-10-producing regulatory $B$ cells, which negatively control immune response, was significantly lower in SSc patients than in healthy controls (35). In addition, levels of regulatory B cell in SSc patients negatively correlated with the titer of anti-topoisomerase I antibody and anti-centromere antibody. Based on the above notion, B cell depleting therapy with rituximab may also be utilized as a promising treatment for SSc (34). In tight skin 
mice, anti-mouse CD20 monoclonal antibody could significantly suppresses the skin fibrosis as well as prevents hypergammaglobulinemia and autoantibody production. Down-regulation of profibrogenic cytokines including TGF- $\beta$ or normalization of Th1/Th2 cytokine balance in the skin was also described $(8,36)$.

To date, many recent reports have indicated that rituximab improved skin sclerosis of dcSSc: for example, as one of the first reports, 15 patients were recruited to receive intravenous doses of rituximab $(1000 \mathrm{mg})$ twice (37). The modest B cell infiltrates that were seen at baseline were completely depleted in the skin and blood of most patients after six months. On the other hand, autoantibody titers were only slightly decreased after the treatment. Furthermore, the mean change in the skin score after six months was not statistically significant (20.6 to $20.2, \mathrm{P}=0.83$ ). Rituximab treatment was concluded to be safe and well tolerated, and effectively depletes both circulating B cells and dermal B cells. However, the drug had little effect on the levels of $\mathrm{SSc}$-associated autoantibodies or skin sclerosis. Nonetheless, a lot of reports of case series have indicated the efficacy for skin sclerosis. In addition, in a EUSTAR group observational study, improvement of skin scores were significantly larger $(\mathrm{P}=0.03)$ in the rituximab group $(n=63,-24.0 \%)$ than matched controls $(n=25 ;-7.7 \%)$ (38). Moreover, in patients treated with rituximab, the mean skin score was also significantly reduced compared with baseline (26.6 vs $20.3, \mathrm{P}=0.0001$ ).

Taken together, additional controlled trials are needed to evaluate both the effects and the side effects. Several phase III studies versus placebo are currently being performed.

\subsection{Intravenous immune globulin}

Intravenous immune globulin (IVIG) is firstly used as treatment of agammaglobulinemia. Subsequently, IVIG was found to be effective for idiopathic thrombocytopenic purpura in the 1980s. The drug has become available for various human autoimmune diseases. Furthermore, the efficacy of IVIG has been reported in many skin diseases including pemphigus, dermatomyositis/polymyositis, or Stevens-Johnson syndrome/epidermal necrolysis because of its more effective therapeutic values and fewer side effects in comparison with conventional treatments.
Although the detailed mechanisms by which IVIG improves autoimmune diseases remain unknown, several hypotheses have been suggested (39). For example, IVIG is thought to exert the effects via the Fc region of $\mathrm{IgG}$. Fc portion competes with autoantibodies in binding to $\mathrm{Fc}$ receptors on the surface of B-cells and macrophages, resulting in the elimination of autoantibodies. Alternatively, the IgG polymer generated by IVIG may compete with immune complexes induced by autoantibodies. IVIG may also modulate lymphocyte functions, cytokine synthesis, or complement activation.

Moreover, IVIG treatment is thought to suppress the expression of chemokines including monocyte chemoattractant protein (MCP)-1, macrophage colony-stimulating factor (M-CSF) and granulocytemacrophage colony stimulating factor (GM-CSF) in fibrotic diseases $(5,40)$. We also found the serum levels of Th1 cytokines (IFN- $\gamma$ and IL-12), not Th2 cytokines, were recovered by the IVIG treatment in SSc patients (41). Blank et al. reported that IVIG administration on tight-skin mice significantly reduced collagen mRNA levels and cutaneous collagen deposition (42). In addition, in mice splenocytes, IVIG treatment reduced the secretion of profibrotic cytokines (TGF- $\beta 1$ and IL-4), but not interferon- $\gamma$.

There have been case series and a small number of open-label, uncontrolled studies suggesting the efficacy of IVIG for SSc skin $(43,44)$, indicating that IVIG may be a promising option. For example, IVIG (400 $\mathrm{mg} / \mathrm{kg}$ daily for five consecutive days) dramatically reduced histological skin fibrosis, and significantly improved the skin score $(\mathrm{P}<0.01)(43)$. A large randomized controlled study has been completed in Japan to further validate the efficacy, but is currently unpublished.

\subsection{Interferon}

Several reports have shown that interferon- $\alpha$ suppresses the expression of type I collagen in SSc dermal fibroblasts in vitro (45). This notion prompted a randomized, double-blind, placebo-controlled trial. However, interferon- $\alpha$ treatment $\left(13.5 \times 10^{6}\right.$ units/week $)$ for one year did not improve skin sclerosis in patients with dcSSc (mean skin score change $=-4.7$ ) compared to placebo (-7.5, $\mathrm{P}=0.36$ ) (46). Furthermore, interferon- $\alpha$ exacerbated ILD. These results are consistent with cases treated with interferon- $\alpha$ and $-\beta$ for the treatment of 
chronic hepatitis $\mathrm{C}$ and multiple sclerosis, who developed SSc and SSc-like disorders (5). Taken together, these clinical and laboratory observations suggest that interferon- $\alpha$ is positively associated with the fibrotic process of SSc, and blockade of interferon- $\alpha$, not interferon supplementation, may be effective (5).

\subsection{Anti-tumor necrosis factor (TNF)- $\alpha$ therapy}

TNF- $\alpha$ is thought to inhibit the production of profibrotic factors and stimulate proteolytic activation, such as MMP expression. There have also been reports describing immune activation by anti-TNF- $\alpha$ therapy in autoimmune diseases, such as lupus- or psoriasis-like symptoms. Furthermore, rheumatoid arthritis-related pulmonary fibrosis can be exacerbated by the therapy (47-49). On the other hand, anti-TNF- $\alpha$ therapies have been beneficial in certain inflammatory bowel diseases that are characterized by inflammation and fibrosis (49).

In the report by Lam et al, 18 female SSc patients with inflammatory joint involvement were treated with etanercept $50 \mathrm{mg} /$ week for 2 to 66 months (mean: 30 months) (50). Eight patients were positive for rheumatoid factors and three had positive anti-cyclic citullinated peptides (CCP) antibodies. In the retrospective cohort study, 15 out of the 18 patients $(83 \%)$ were considered as responders with a decrease in inflammation of joints. On the other hand, the skin score decreased from 6.6 to 3.9 , but the change was not significant $(\mathrm{P}=0.12)$. In another open-label study of $16 \mathrm{dcSSc}$ patients with progressive skin sclerosis, infliximab at a dose of $5 \mathrm{mg} / \mathrm{kg}$ at five courses was tested, but the effect on skin score was only slight at 26 weeks (from 26 to 22) $(49,51)$. Serum levels of propeptide of collagen III and collagen I were significantly reduced after the treatment compared with the baseline. The expression of TGF- $\beta$ in lesional skin biopsies was not be affected by the treatment (51). Bosello et al. reported that infliximab $(3 \mathrm{mg} / \mathrm{kg})$ at four times together with methotrexate, followed by etanercept (25 mg) improved skin score in four patients with SSc (35 to 16,12 to 7,16 to 7 , and 8 to 3 ), albeit insignificantly (52). Accordingly, there is still not enough evidence to show the effect of anti-TNF therapy against skin involvement. The EUSTAR group do not recommend use of this drug $(49,53)$. Treatment-related death was rarely reported (47), and long-term tolerance of anti-TNF- $\alpha$ in SSc patients should be examined in the future.

\subsection{Imatinib}

A protein tyrosine kinase inhibitor, imatinib mesylate, blocks c-kit and PDGF receptor. Imatinib also inhibits non-canonical TGF- $\beta$ signaling through $c-A b l$, which is one of the important downstream molecules of the TGF- $\beta$ pathway. Imatinib is currently used for the treatment of chronic myeloid leukemia and gastrointestinal stromal tumors.

Imatinib mesylate is given attention for its possible application as a novel therapy against fibrosis and vasculopathy in SSc, because the drug can reverse the expression of Fli1, which is a key transcription factor controlling fibrosis and vasculopathy as well as immune dysfunction of this disease $(5,54,55)$. Side effects include myelosuppression, headache, nausea, vomiting, diarrhea, and edema.

TGF- $\beta$ and PDGF signaling is also involved in the fibrosis seen in SSc, and the drug may be able to inhibit fibrotic process of SSc by blocking them both. The inhibition of the pathway could decrease the mRNA and protein expression of collagen in both normal and SSc dermal fibroblasts $(8,56)$. Furthermore, imatinib reduced skin thickening of tight-skin mice, and prevented the differentiation of resting fibroblasts into myofibroblasts (57). Notably, imatinib not only stopped further progression of established dermal fibrosis, but also induced regression of existing fibrosis. (49).

Case reports have indicated the effect of imatinib on skin sclerosis. Several open-label studies also reported significant decrease of skin score (58). However, the effects were not significant in a six-month randomized double-blind control study (400 mg/day of imatinib) of 28 patients $(\mathrm{P}=0.098)$ (59), double-blind study (400 $\mathrm{mg} /$ day) of $10 \mathrm{SSc}$ patients, and open-label study (200 $\mathrm{mg} /$ day) of 30 patients $(60,61)$.

\section{Future treatments}

According to ClinicalTrials (https://clinicaltrials. gov), placebo-controlled randomized clinical trials of several drugs other than those described above, including abatacept or ethanol extract physalis angulata linn, targeted skin sclerosis, and have already been completed. 
Trial of brentuximab vedotin, riociguat study for dcSSc (RISE-SSc) (62) or pirfenidone is still ongoing.

On the other hand, several drugs have been proven to have therapeutic potential by open-label studies. For example basiliximab, CD25 monoclonal antibody, has improved skin sclerosis (63). Furthermore, belimumab (antibody for B-lymphocyte stimulator), dasatinib, and nilotinib (Abl tyrosine kinase and PDGF receptor inhibitors) (49), antibody against lymphotoxin- $\alpha,-\beta$, CD40L, CD27L, FasL, OX40L, or tumor necrosis factor superfamily (TRAIL) (8) are speculated to have anti-fibrotic effects. Guideline of SSc was published by a Japanese group in 2018 (64), and evidence of various treatments has been analyzed and evaluated. Further investigation of the effects of novel drugs will contribute to the treatment of skin sclerosis in SSc.

\section{Acknowledgements}

We acknowledge proofreading by Benjamin Phillis.

\section{References}

1. Korn JH. Immunologic aspects of scleroderma. Curr Opin Rheumatol. 1989; 1 (4): 479-84. PubMed PMID: 2702049.

2. Mauch C, Kreig T. Fibroblast-matrix interactions and their role in the pathogenesis of fibrosis. Rheum Dis Clin North Am. 1990; 16 (1): 93-107. PubMed PMID: 2406813.

3. LeRoy EC, Black C, Fleischmajer R, Jablonska S, Krieg T, Medsger TA, et al. Scleroderma (systemic sclerosis): classification, subsets and pathogenesis. J Rheumatol. 1988; 15 (2): 202-5. PubMed PMID: 3361530.

4. Steen VD, Medsger TA. Long-term outcomes of scleroderma renal crisis. Ann Intern Med. 2000; 133(8): 600-3. PubMed PMID: 11033587.

5. Asano Y. Future treatments in systemic sclerosis. J Dermatol. 2010; 37 (1): 54-70. doi: 10.1111/j. 1346-8138.2009.00758.x. PubMed PMID: 2017 5840 .

6. Sharada B, Kumar A, Kakker R, Adya CM, Pande I, Uppal SS, et al. Intravenous dexamethasone pulse therapy in diffuse systemic sclerosis. A randomized placebo-controlled study. Rheumatol Int. 1994; 14 (3): 91-4. PubMed PMID: 7839076.

7. Takehara K. Treatment of early diffuse cutaneous systemic sclerosis patients in Japan by low-dose corticosteroids for skin involvement. Clin Exp Rheumatol. 2004; 22 (3 Suppl 33): S87-9. PubMed PMID: 15344605.

8. Raja J, Denton CP. Cytokines in the immunopathology of systemic sclerosis. Semin Immunopathol. 2015; 37 (5): 543-57. Epub 2015/07/08. doi: 10.1007/s00281-015-0511-7. PubMed PMID: 2615 2640.

9. Jinnin M. Mechanisms of skin fibrosis in systemic sclerosis. J Dermatol. 2010; 37 (1): 11-25. doi: 10.1111/j.1346-8138.2009.00738.x. PubMed PMID: 20175837.

10. Tashkin DP, Elashoff R, Clements PJ, Goldin J, Roth MD, Furst DE, et al. Cyclophosphamide versus placebo in scleroderma lung disease. $\mathrm{N}$ Engl $\mathrm{J}$ Med. 2006; 354 (25): 2655-66. doi: 10.1056/ NEJMoa055120. PubMed PMID: 16790698.

11. Tashkin DP, Elashoff R, Clements PJ, Roth MD, Furst DE, Silver RM, et al. Effects of 1-year treatment with cyclophosphamide on outcomes at 2 years in scleroderma lung disease. Am J Respir Crit Care Med. 2007; 176 (10): 1026-34. Epub 2007/08 123. doi: 10.1164/rccm.200702-326OC. PubMed PMID: 17717203; PubMed Central PMCID: PMCPMC2078679.

12. Davas EM, Peppas C, Maragou M, Alvanou E, Hondros D, Dantis PC. Intravenous cyclophosphamide pulse therapy for the treatment of lung disease associated with scleroderma. Clin Rheumatol. 1999; 18 (6): 455-61. PubMed PMID: 10638770.

13. Hoyles RK, Ellis RW, Wellsbury J, Lees B, Newlands P, Goh NS, et al. A multicenter, prospective, randomized, double-blind, placebo-controlled trial of corticosteroids and intravenous cyclophosphamide followed by oral azathioprine for the treatment of pulmonary fibrosis in scleroderma. Arthritis Rheum. 2006; 54 (12): 3962-70. doi: 10.1002/ art.22204. PubMed PMID: 17133610.

14. Griffiths B, Miles S, Moss H, Robertson R, Veale D, Emery P. Systemic sclerosis and interstitial lung disease: a pilot study using pulse intravenous methylprednisolone and cyclophosphamide to assess the effect on high resolution computed tomography scan and lung function. J Rheumatol. 2002; 29 (11): 2371-8. PubMed PMID: 12415594.

15. Balbir-Gurman A, Yigla M, Guralnik L, Hardak E, Solomonov A, Rozin AP, et al. Long-term follow-up of patients with scleroderma interstitial lung disease treated with intravenous cyclophosphamide pulse therapy: a single-center experience. Isr Med Assoc J. 2015; 17 (3): 150-6. PubMed PMID: 25946765.

16. Filaci G, Cutolo M, Scudeletti M, Castagneto C, Derchi L, Gianrossi R, et al. Cyclosporin A and iloprost treatment of systemic sclerosis: clinical results and interleukin-6 serum changes after 12 months of therapy. Rheumatology (Oxford). 1999; 38 (10): 992-6. PubMed PMID: 10534551.

17. van den Hoogen FH, Boerbooms AM, Swaak AJ, Rasker JJ, van Lier HJ, van de Putte LB. Comparison of methotrexate with placebo in the treatment of systemic sclerosis: a 24 week randomized double-blind trial, followed by a 24 week observational trial. Br J Rheumatol. 1996; 35 (4): 364-72. Pub- 
Med PMID: 8624641.

18. Pope JE, Bellamy N, Seibold JR, Baron M, Ellman $\mathrm{M}$, Carette $\mathrm{S}$, et al. A randomized, controlled trial of methotrexate versus placebo in early diffuse scleroderma. Arthritis Rheum. 2001; 44 (6): 1351-8. doi: 10.1002/1529-0131(200106)44:6\&lt;1351::AI D-ART227\&gt;3.0.CO;2-I. PubMed PMID: 11407 694.

19. Derk CT, Grace E, Shenin M, Naik M, Schulz S, Xiong W. A prospective open-label study of mycophenolate mofetil for the treatment of diffuse systemic sclerosis. Rheumatology (Oxford). 2009; 48(12): 1595-9. Epub 2009/10/21. doi: 10.1093 /rheumatology/kep295. PubMed PMID: 19846575.

20. Nihtyanova SI, Brough GM, Black CM, Denton CP. Mycophenolate mofetil in diffuse cutaneous systemic sclerosis--a retrospective analysis. Rheumatology (Oxford). 2007; 46 (3): 442-5. Epub 2006/08/09. doi: 10.1093/rheumatology/kel244. PubMed PMID: 16899504.

21. Morton SJ, Powell RJ. Cyclosporin and tacrolimus: their use in a routine clinical setting for scleroderma. Rheumatology (Oxford). 2000; 39 (8): 865-9. PubMed PMID: 10952740.

22. Nadashkevich O, Davis P, Fritzler M, Kovalenko W. A randomized unblinded trial of cyclophosphamide versus azathioprine in the treatment of systemic sclerosis. Clin Rheumatol. 2006; 25 (2): 205-12. Epub 2005/10/14. doi: 10.1007/s10067-005-1157-y. PubMed PMID: 16228107.

23. Matteson EL, Shbeeb MI, McCarthy TG, Calamia KT, Mertz LE, Goronzy JJ. Pilot study of antithymocyte globulin in systemic sclerosis. Arthritis Rheum. 1996; 39 (7): 1132-7. PubMed PMID: 8670321.

24. Stratton RJ, Wilson H, Black CM. Pilot study of anti-thymocyte globulin plus mycophenolate mofetil in recent-onset diffuse scleroderma. Rheumatology (Oxford). 2001; 40(1): 84-8. PubMed PMID: 11157146.

25. de Clerck LS, Dequeker J, Francx L, Demedts M. D-penicillamine therapy and interstitial lung disease in scleroderma. A long-term followup study. Arthritis Rheum. 1987; 30 (6): 643-50. PubMed PMID: 3606683.

26. Steen VD, Medsger TA, Rodnan GP. D-Penicillamine therapy in progressive systemic sclerosis (scleroderma): a retrospective analysis. Ann Intern Med. 1982; 97 (5):652-9. PubMed PMID: 7137731.

27. Jayson MI, Lovell C, Black CM, Wilson RS. Penicillamine therapy in systemic sclerosis. Proc R Soc Med. 1977; 70 Suppl 3: 82-8. PubMed PMID: 122683; PubMed Central PMCID: PMCPMC154 3570 .

28. Clements PJ, Furst DE, Wong WK, Mayes M, White B, Wigley $\mathrm{F}$, et al. High-dose versus low-dose D-penicillamine in early diffuse systemic sclerosis: analysis of a two-year, double-blind, randomized, controlled clinical trial. Arthritis Rheum. 1999; 42 (6): 1194-203. doi: 10.1002/1529-0131 (199906)42:6\&lt;1194::AID-ANR16\&gt;3.0.CO;27. PubMed PMID: 10366112.

29. Derk CT, Huaman G, Jimenez SA. A retrospective randomly selected cohort study of D-penicillamine treatment in rapidly progressive diffuse cutaneous systemic sclerosis of recent onset. Br J Dermatol. 2008; 158 (5): 1063-8. Epub 2008/02/16. doi: 10.1111/j.1365-2133.2008.08452.x. PubMed PMID: 18284395.

30. Sato S, Hasegawa M, Takehara K. Serum levels of interleukin-6 and interleukin-10 correlate with total skin thickness score in patients with systemic sclerosis. J Dermatol Sci. 2001;27 (2):140-6. PubMed PMID: 11532378.

31. Duncan MR, Berman B. Stimulation of collagen and glycosaminoglycan production in cultured human adult dermal fibroblasts by recombinant human interleukin 6. J Invest Dermatol. 1991; 97(4): 686-92. PubMed PMID: 1940439.

32. Khanna D, Denton CP, Jahreis A, van Laar JM, Frech TM, Anderson ME, et al. Safety and efficacy of subcutaneous tocilizumab in adults with systemic sclerosis (faSScinate): a phase 2, randomised, controlled trial. Lancet. 2016; 387 (10038): 2630040. Epub 2016/05/05. doi: 10.1016/S0140-6736(16) 00232-4. PubMed PMID: 27156934.

33. Khanna D, Denton CP, Lin CJF, van Laar JM, Frech TM, Anderson ME, et al. Safety and efficacy of subcutaneous tocilizumab in systemic sclerosis: results from the open-label period of a phase II randomised controlled trial (faSScinate). Ann Rheum Dis. 2018; 77 (2): 212-20. Epub 2017/10/24. doi: 10.1136/annrheumdis-2017-211682. PubMed PMID: 29066464; PubMed Central PMCID: PMCPMC5867414.

34. Yoshizaki A. B cell abnormalities and therapeutic strategies in systemic sclerosis. Nihon Rinsho Meneki Gakkai Kaishi. 2016; 39 (3): 197-206. doi: 10.2177/jsci.39.197. PubMed PMID: 27320935.

35. Matsushita T, Hamaguchi Y, Hasegawa M, Takehara K, Fujimoto M. Decreased levels of regulatory B cells in patients with systemic sclerosis: association with autoantibody production and disease activity. Rheumatology (Oxford). 2016; 55 (2): 263-7. Epub 2015/09/08. doi: 10.1093/rheumatology/kev331. PubMed PMID: 26350483.

36. Hasegawa M, Hamaguchi Y, Yanaba K, Bouaziz JD Uchida J, Fujimoto M, et al. B-lymphocyte depletion reduces skin fibrosis and autoimmunity in the tight-skin mouse model for systemic sclerosis. Am J Pathol. 2006; 169 (3): 954-66. doi: 10.2353/ajpath.2006.060205. PubMed PMID: 16936269; PubMed Central PMCID: PMCPMC1698806.

37. Lafyatis R, Kissin E, York M, Farina G, Viger K, Fritzler MJ, et al. B cell depletion with rituximab in 
patients with diffuse cutaneous systemic sclerosis. Arthritis Rheum. 2009; 60 (2): 578-83. doi: 10.1002/art.24249. PubMed PMID: 19180481; PubMed Central PMCID: PMCPMC2637937.

38. Jordan S, Distler JH, Maurer B, Huscher D, van Laar JM, Allanore Y, et al. Effects and safety of rituximab in systemic sclerosis: an analysis from the European Scleroderma Trial and Research (EUSTAR) group. Ann Rheum Dis. 2015; 74 (6): 1188-94. doi: 10.1136/annrheumdis-2013-204522. PubMed PMID: 24442885.

39. Ballow M. Mechanisms of action of intravenous immune serum globulin in autoimmune and inflammatory diseases. J Allergy Clin Immunol. 1997; 100 (2): 151-7. PubMed PMID: 9275133.

40. Amital H, Rewald E, Levy Y, Bar-Dayan Y, Manthorpe R, Engervall $\mathrm{P}$, et al. Fibrosis regression induced by intravenous gammaglobulin treatment. Ann Rheum Dis. 2003; 62 (2): 175-7. PubMed PMID: 12525390; PubMed Central PMCID: PMCPMC1754436.

41. Kudo H, Jinnin M, Yamane K, Makino T, Kajihara I, Makino $\mathrm{K}$, et al. Intravenous immunoglobulin treatment recovers the down-regulated levels of Th1 cytokines in the sera and skin of scleroderma patients. J Dermatol Sci. 2013; 69 (1): 77-80. doi: 10.1016/j.jdermsci.2012.09.010. PubMed PMID: 23102713.

42. Blank M, Levy Y, Amital H, Shoenfeld Y, Pines M, Genina O. The role of intravenous immunoglobulin therapy in mediating skin fibrosis in tight skin mice. Arthritis Rheum. 2002; 46 (6): 1689-90. doi: 10.1002/art.10363. PubMed PMID: 12115202.

43. Asano Y, Ihn H, Asashima N, Yazawa N, Mimura Y, Jinnin $\mathrm{M}$, et al. A case of diffuse scleroderma successfully treated with high-dose intravenous immune globulin infusion. Rheumatology (Oxford). 2005; 44 (6): 824-6. Epub 2005/03/15. doi: 10.1093/rheumatology/keh600. PubMed PMID: 15769789.

44. Ihn H, Mimura Y, Yazawa N, Jinnin M, Asano Y, Yamane $\mathrm{K}$, et al. High-dose intravenous immunoglobulin infusion as treatment for diffuse scleroderma. Br J Dermatol. 2007; 156 (5): 1058-60. Epub 2007/03/23. doi: 10.1111/j.1365-2133.2007. 07777.x. PubMed PMID: 17381465.

45. Kähäri VM, Heino J, Vuorio T, Vuorio E. Interferon-alpha and interferon-gamma reduce excessive collagen synthesis and procollagen mRNA levels of scleroderma fibroblasts in culture. Biochim Biophys Acta. 1988; 968 (1): 45-50. PubMed PMID: 3122841.

46. Black CM, Silman AJ, Herrick AI, Denton CP, Wilson H, Newman J, et al. Interferon-alpha does not improve outcome at one year in patients with diffuse cutaneous scleroderma: results of a randomized, double-blind, placebo-controlled trial. Arthritis Rheum. 1999; 42 (2): 299-305. doi:
10.1002/1529-0131(199902)42:2\&lt;299::AID-AN R12\&gt;3.0.CO;2-R. PubMed PMID: 10025924.

47. Allanore Y, Devos-François G, Caramella C, Boumier P, Jounieaux V, Kahan A. Fatal exacerbation of fibrosing alveolitis associated with systemic sclerosis in a patient treated with adalimumab. Ann Rheum Dis. 2006; 65 (6): 834-5. doi: 10.1136/ard.2005.044453. PubMed PMID: 16699057; PubMed Central PMCID: PMCPMC1798181.

48. Ramos-Casals M, Perez-Alvarez R, Perez-de-Lis M, Xaubet A, Bosch X, Group BS. Pulmonary disorders induced by monoclonal antibodies in patients with rheumatologic autoimmune diseases. Am J Med. 2011; 124 (5): 386-94. doi: 10.1016/j.amjmed. 2010.11.028. PubMed PMID: 21531225.

49. Avouac J, Allanore Y. Targeted immunotherapies in systemic sclerosis. Clin Exp Rheumatol. 2014; 32 (2 Suppl 81):165-72. Epub 2014/04/15. PubMed PMID: 24742451.

50. Lam GK, Hummers LK, Woods A, Wigley FM. Efficacy and safety of etanercept in the treatment of scleroderma-associated joint disease. J Rheumatol. 2007; 34 (7):1636-7. PubMed PMID: 17611970.

51. Denton CP, Engelhart M, Tvede N, Wilson H, Khan $\mathrm{K}$, Shiwen X, et al. An open-label pilot study of infliximab therapy in diffuse cutaneous systemic sclerosis. Ann Rheum Dis. 2009; 68 (9):1433-9. Epub 2008/09/09. doi: 10.1136/ard.2008.096123. PubMed PMID: 18782794.

52. Bosello S, De Santis M, Tolusso B, Zoli A, Ferraccioli G. Tumor necrosis factor-alpha inhibitor therapy in erosive polyarthritis secondary to systemic sclerosis. Ann Intern Med. 2005; 143 (12): 918-20. PubMed PMID: 16365478.

53. Distler JH, Jordan S, Airo P, Alegre-Sancho JJ, Allanore Y, Balbir Gurman A, et al. Is there a role for TNF $\alpha$ antagonists in the treatment of SSc? EUSTAR expert consensus development using the Delphi technique. Clin Exp Rheumatol. 2011; 29 (2 Suppl 65): S40-5. Epub 2011/05/12. PubMed PMID: 21586217.

54. Asano Y, Bujor AM, Trojanowska M. The impact of Fli1 deficiency on the pathogenesis of systemic sclerosis. J Dermatol Sci. 2010; 59 (3):153-62. doi: 10.1016/j.jdermsci.2010.06.008. PubMed PMID: 20663647; PubMed Central PMCID: PMCPMC 3826615.

55. Noda S, Asano Y, Nishimura S, Taniguchi T, Fujiu $\mathrm{K}$, Manabe I, et al. Simultaneous downregulation of KLF5 and Fli1 is a key feature underlying systemic sclerosis. Nat Commun. 2014; 5: 5797. doi: 10.1038/ncomms6797. PubMed PMID: 25504335; PubMed Central PMCID: PMCPMC4268882.

56. Distler JH, Jüngel A, Huber LC, Schulze-Horsel U, Zwerina J, Gay RE, et al. Imatinib mesylate reduces production of extracellular matrix and prevents development of experimental dermal fibrosis. Ar- 
thritis Rheum. 2007; 56 (1): 311-22. doi: 10.1002/art.22314. PubMed PMID: 17195235.

57. Akhmetshina A, Venalis P, Dees C, Busch N, Zwerina J, Schett G, et al. Treatment with imatinib prevents fibrosis in different preclinical models of systemic sclerosis and induces regression of established fibrosis. Arthritis Rheum. 2009; 60 (1): 21924. doi: 10.1002/art.24186. PubMed PMID: 1911 6940.

58. Gordon J, Udeh U, Doobay K, Magro C, Wildman $\mathrm{H}$, Davids $\mathrm{M}$, et al. Imatinib mesylate (Gleevec) in the treatment of diffuse cutaneous systemic sclerosis: results of a 24-month open label, extension phase, single-centre trial. Clin Exp Rheumatol. 2014; 32 (6 Suppl 86): S-189-93. Epub 2014/08/15. PubMed PMID: 25152211.

59. Prey S, Ezzedine K, Doussau A, Grandoulier AS, Barcat D, Chatelus E, et al. Imatinib mesylate in scleroderma-associated diffuse skin fibrosis: a phase II multicentre randomized double-blinded controlled trial. Br J Dermatol. 2012; 167 (5): 1138-44. doi: 10.1111/j.1365-2133.2012. 11186.x. PubMed PMID: 23039171.

60. Pope J, McBain D, Petrlich L, Watson S, Vanderhoek L, de Leon F, et al. Imatinib in active diffuse cutaneous systemic sclerosis: Results of a six-month, randomized, double-blind, placebo-controlled, proof-of-concept pilot study at a single center. Arthritis Rheum. 2011; 63 (11):3547-51. doi: 10.1002/art.30549. PubMed PMID: 21769850.

61. Fraticelli P, Gabrielli B, Pomponio G, Valentini G, Bosello S, Riboldi P, et al. Low-dose oral imatinib in the treatment of systemic sclerosis interstitial lung disease unresponsive to cyclophosphamide: a phase II pilot study. Arthritis Res Ther. 2014; 16(4): R144. Epub 2014/07/08. doi: 10.1186/ar4606. PubMed PMID: 25007944; PubMed Central PMCID: PMCPMC4227120.

62. Distler O, Pope J, Denton C, Allanore Y, Matucci-Cerinic M, de Oliveira Pena J, et al. RISE-SSc: Riociguat in diffuse cutaneous systemic sclerosis. Respir Med. 2017; 122 Suppl 1: S14-S7. Epub 2016/09/28. doi: 10.1016/j.rmed.2016.09.011. PubMed PMID: 27746061.

63. Scherer HU, Burmester GR, Riemekasten G. Targeting activated $T$ cells: successful use of anti-CD25 monoclonal antibody basiliximab in a patient with systemic sclerosis. Ann Rheum Dis. 2006; 65 (9): 1245-7. doi: 10.1136/ard.2005.046938. PubMed PMID: 16905582; PubMed Central PMCID: PMCPMC1798302.

64. Asano Y, Jinnin M, Kawaguchi Y, Kuwana M, Goto $\mathrm{D}$, Sato S, et al. Diagnostic criteria, severity classification and guidelines of systemic sclerosis. J Dermatol. 2018; 45 (6): 633-91. Epub 2018/04/23. doi: 10.1111/1346-8138.14162. PubMed PMID: 29687465. 